\title{
Promoting critical thinking through an evidence-based skills fair intervention
}

\author{
Heidi C. Gonzalez, E-Ling Hsiao and Dianne C. Dees \\ Valdosta State University, Valdosta, Georgia, USA \\ Sherri R. Noviello \\ Georgia College and State University, Milledgeville, Georgia, USA, and \\ Brian L. Gerber \\ Valdosta State University, Valdosta, Georgia, USA
}

\begin{abstract}
Purpose - The lack of critical thinking in new graduates has been a concern to the nursing profession. The purpose of this study was to investigate the effects of an innovative, evidence-based skills fair intervention on nursing students' achievements and perceptions of critical thinking skills development.

Design/methodology/approach - The explanatory sequential mixed-methods design was employed for this study.

Findings - The findings indicated participants perceived the intervention as a strategy for developing critical thinking.

Originality/value - The study provides educators helpful information in planning their own teaching practice in educating students.
\end{abstract}

Keywords Critical thinking, Evidence-based practice, Skills fair intervention

Paper type Research paper

\section{Introduction}

Critical thinking (CT) was defined as "cognitive skills of analyzing, applying standards, discriminating, information seeking, logical reasoning, predicting, and transforming knowledge" (Scheffer and Rubenfeld, 2000, p. 357). Critical thinking is the basis for all professional decision-making (Moore, 2007). The lack of critical thinking in student nurses and new graduates has been a concern to the nursing profession. It would negatively affect the quality of service and directly relate to the high error rates in novice nurses that influence patient safety (Arli et al., 2017; Saintsing et al., 2011). It was reported that as many as $88 \%$ of novice nurses commit medication errors with $30 \%$ of these errors due to a lack of critical thinking (Ebright et al., 2004). Failure to rescue is another type of error common for novice nurses, reported as high as 37\% (Saintsing et al., 2011). The failure to recognize trends or complications promptly or take action to stabilize the patient occurs when health-care providers do not recognize signs and symptoms of the early warnings of distress (Garvey and CNE series, 2015). Internationally, this lack of preparedness and critical thinking attributes to the reported 35-60\% attrition rate of new graduate nurses in their first two years of practice (Goodare, 2015). The high attrition rate of new nurses has

(C) Heidi C. Gonzalez, E-Ling Hsiao, Dianne C. Dees, Sherri R. Noviello and Brian L. Gerber. Published in Journal of Research in Innovative Teaching \& Learning. Published by Emerald Publishing Limited. This article is published under the Creative Commons Attribution (CC BY 4.0) licence. Anyone may reproduce, distribute, translate and create derivative works of this article (for both commercial and noncommercial purposes), subject to full attribution to the original publication and authors. The full terms of this licence may be seen at http://creativecommons.org/licences/by/4.0/legalcode

An evidencebased skills fair intervention

Received 27 August 2020 Revised 30 October 2020 Accepted 30 October 2020 
JRIT

15,1

expensive professional and economic costs of $\$ 82,000$ or more per nurse and negatively affects patient care (Twibell et al., 2012). Facione and Facione (2013) reported the failure to utilize critical thinking skills not only interferes with learning but also results in poor decision-making and unclear communication between health-care professionals, which ultimately leads to patient deaths.

Due to the importance of critical thinking, many nursing programs strive to infuse critical thinking into their curriculum to better prepare graduates for the realities of clinical practice that involves ever-changing, complex clinical situations and bridge the gap between education and practice in nursing (Benner et al., 2010; Kim et al., 2019; Park et al., 2016; Newton and Moore, 2013; Nibert, 2011). To help develop students' critical thinking skills, nurse educators must change the way they teach nursing, so they can prepare future nurses to be effective communicators, critical thinkers and creative problem solvers (Rieger et al., 2015). Nursing leaders also need to redefine teaching practice and educational guidelines that drive innovation in undergraduate nursing programs.

Evidence-based practice has been advocated to promote critical thinking and help reduce the research-practice gap (Profetto-McGrath, 2005; Stanley and Dougherty, 2010). Evidencebased practice was defined as "the conscientious, explicit, and judicious use of current best evidence in making decisions about the care of the individual patient" (Sackett et al., 1996, p. 71). Skills fair intervention, one type of evidence-based practice, can be used to engage students, promote active learning and develop critical thinking (McCausland and Meyers, 2013; Roberts et al., 2009). Skills fair intervention helps promote a consistent teaching practice of the psychomotor skills to the novice nurse that decreased anxiety, gave clarity of expectations to the students in the clinical setting and increased students' critical thinking skills (Roberts et al., 2009). The researchers of this study had an opportunity to create an active, innovative skills fair intervention for a baccalaureate nursing program in one southeastern state. This intervention incorporated evidence-based practice rationale with critical thinking prompts using Socratic questioning, evidence-based practice videos to the psychomotor skill rubrics, group work, guided discussions, expert demonstration followed by guided practice and blended learning in an attempt to promote and develop critical thinking in nursing students (Hsu and Hsieh, 2013; Oermann et al., 2011; Roberts et al., 2009). The effects of an innovative skills fair intervention on senior baccalaureate nursing students' achievements and their perceptions of critical thinking development were examined in the study.

\section{Literature review \\ Critical thinking}

The ability to use reasoned opinion focusing equally on processes and outcomes over emotions is called critical thinking (Paul and Elder, 2008). Critical thinking skills are desired in almost every discipline and play a major role in decision-making and daily judgments. The roots of critical thinking date back to Socrates 2,500 years ago and can be traced to the ancient philosopher Aristotle (Paul and Elder, 2012). Socrates challenged others by asking inquisitive questions in an attempt to challenge their knowledge. In the 1980s, critical thinking gained nationwide recognition as a behavioral science concept in the educational system (Robert and Petersen, 2013). Many researchers in both education and nursing have attempted to define, measure and teach critical thinking for decades. However, a theoretical definition has yet to be accepted and established by the nursing profession (Romeo, 2010). The terms critical literacy, CT, reflective thinking, systems thinking, clinical judgment and clinical reasoning are used synonymously in the reviewed literature (Clarke and Whitney, 2009; Dykstra, 2008; Jones, 2010; Swing, 2014; Turner, 2005). 
Watson and Glaser (1980) viewed critical thinking not only as cognitive skills but also as a combination of skills, knowledge and attitudes. Paul (1993), the founder of the Foundation for Critical Thinking, offered several definitions of critical thinking and identified three essential components of critical thinking: elements of thought, intellectual standards and affective traits. Brunt (2005) stated critical thinking is a process of being practical and considered it to be "the process of purposeful thinking and reflective reasoning where practitioners examine ideas, assumptions, principles, conclusions, beliefs, and actions in the contexts of nursing practice" (p. 61). In an updated definition, Ennis (2011) described critical thinking as, "reasonable reflective thinking focused on deciding what to believe or do" (para. 1).

The most comprehensive attempt to define critical thinking was under the direction of Facione and sponsored by the American Philosophical Association (Scheffer and Rubenfeld, 2000). Facione (1990) surveyed 53 experts from the arts and sciences using the Delphi method to define critical thinking as a "purposeful, self-regulatory judgment which results in interpretation, analysis, evaluation, and inference, as well as an explanation of the evidential, conceptual, methodological, criteriological, or contextual considerations upon which judgment, is based" (p. 2).

To come to a consensus definition for critical thinking, Scheffer and Rubenfeld (2000) also conducted a Delphi study. Their study consisted of an international panel of nurses who completed five rounds of sequenced questions to arrive at a consensus definition. Critical thinking was defined as "habits of mind" and "cognitive skills." The elements of habits of mind included "confidence, contextual perspective, creativity, flexibility, inquisitiveness, intellectual integrity, intuition, open-mindedness, perseverance, and reflection" (Scheffer and Rubenfeld, 2000, p. 352). The elements of cognitive skills were recognized as "analyzing, applying standards, discriminating, information seeking, logical reasoning, predicting, and transforming knowledge" (Scheffer and Rubenfeld, 2000, p. 352). In addition, Ignatavicius (2001) defined the development of critical thinking as a long-term process that must be practiced, nurtured and reinforced over time. Ignatavicius believed that a critical thinker required six cognitive skills: interpretation, analysis, evaluation, inference, explanation and self-regulation (Chun-Chih et al., 2015). According to Ignatavicius (2001), the development of critical thinking is difficult to measure or describe because it is a formative rather than summative process.

Fero et al. (2009) noted that patient safety might be compromised if a nurse cannot provide clinically competent care due to a lack of critical thinking. The Institute of Medicine (2001) recommended five health care competencies: patient-centered care, interdisciplinary team care, evidence-based practice, informatics and quality improvement. Understanding the development and attainment of critical thinking is the key for gaining these future competencies (Scheffer and Rubenfeld, 2000). The development of a strong scientific foundation for nursing practice depends on habits such as contextual perspective, inquisitiveness, creativity, analysis and reasoning skills. Therefore, the need to better understand how these critical thinking habits are developed in nursing students needs to be explored through additional research (Fero et al., 2009). Despite critical thinking being listed since the 1980s as an accreditation outcome criteria for baccalaureate programs by the National League for Nursing, very little improvement has been observed in practice (McMullen and McMullen, 2009). James (2013) reported the number of patient harm incidents associated with hospital care is much higher than previously thought. James' study indicated that between 210,000 and 440,000 patients each year go to the hospital for care and end up suffering some preventable harm that contributes to their death. James' study of preventable errors is attributed to other sources besides nursing care, but having a nurse in place who can advocate and critically think for patients will make a positive impact on improving patient safety (James, 2013; Robert and Peterson, 2013). 
JRIT
15,1

\section{Evidence-based practice}

Adopting teaching practice to promote $\mathrm{CT}$ is a crucial component of nursing education. Research by Nadelson and Nadelson (2014) suggested evidence-based practice is best learned when integrated into multiple areas of the curriculum. Evidence-based practice developed its roots through evidence-based medicine, and the philosophical origins extend back to the mid19th century (Longton, 2014). Florence Nightingale, the pioneer of modern nursing, used evidence-based practice during the Crimean War when she recognized a connection between poor sanitary conditions and rising mortality rates of wounded soldiers (Rahman and Applebaum, 2011). In professional nursing practice today, a commonly used definition of evidence-based practice is derived from Dr. David Sackett: the conscientious, explicit and judicious use of current best evidence in making decisions about the care of the individual patient (Sackett et al., 1996, p. 71). As professional nurses, it is imperative for patient safety to remain inquisitive and ask if the care provided is based on available evidence. One of the core beliefs of the American Nephrology Nurses' Association's (2019) 2019-2020 Strategic Plan is "Anna must support research to develop evidence-based practice, as well as to advance nursing science, and that as individual members, we must support, participate in, and apply evidence-based research that advances our own skills, as well as nursing science" (p. 1). Longton (2014) reported the lack of evidence-based practice in nursing resulted in negative outcomes for patients. In fact, when evidence-based practice was implemented, changes in policies and procedures occurred that resulted in decreased reports of patient harm and associated health-care costs. The Institute of Medicine (2011) recommendations included nurses being leaders in the transformation of the health-care system and achieving higher levels of education that will provide the ability to critically analyze data to improve the quality of care for patients. Student nurses must be taught to connect and integrate CT and evidence-based practice throughout their program of study and continue that practice throughout their careers.

\section{Skills fair intervention}

One type of evidence-based practice that can be used to engage students, promote active learning and develop critical thinking is skills fair intervention (McCausland and Meyers, 2013; Roberts et al., 2009). Skills fair intervention promoted a consistent teaching approach of the psychomotor skills to the novice nurse that decreased anxiety, gave clarity of expectations to the students in the clinical setting and increased students' critical thinking skills (Roberts et al., 2009). The skills fair intervention used in this study is a teaching strategy that incorporated CT prompts, Socratic questioning, group work, guided discussions, return demonstrations and blended learning in an attempt to develop CT in nursing students (Hsu and Hsieh, 2013; Roberts et al., 2009). It melded evidence-based practice with simulated CT opportunities while students practiced essential psychomotor skills.

\section{Research methodology}

Context - skills fair intervention

According to Roberts et al. (2009), psychomotor skills decline over time even among licensed experienced professionals within as little as two weeks and may need to be relearned within two months without performing a skill. When applying this concept to student nurses for whom each skill is new, it is no wonder their competency result is diminished after having a summer break from nursing school. This skills fair intervention is a one-day event to assist baccalaureate students who had taken the summer off from their studies in nursing and all faculty participated in operating the stations. It incorporated evidence-based practice rationale with critical thinking prompts using Socratic questioning, evidence-based practice 
videos to the psychomotor skill rubrics, group work, guided discussions, expert demonstration followed by guided practice and blended learning in an attempt to promote and develop critical thinking in baccalaureate students.

Students were scheduled and placed randomly into eight teams based on attributes of critical thinking as described by Wittmann-Price (2013): Team A - Perseverance, Team B Flexibility, Team C - Confidence, Team D - Creativity, Team E - Inquisitiveness, Team F Reflection, Team $\mathrm{G}$ - Analyzing and Team $\mathrm{H}$ - Intuition. The students rotated every 20 minutes through eight stations: Medication Administration: Intramuscular and Subcutaneous Injections, Initiating Intravenous Therapy, ten-minute Focused Physical Assessment, Foley Catheter Insertion, Nasogastric Intubation, Skin Assessment/Braden Score and Restraints, Vital Signs and a Safety Station. When the students completed all eight stations, they went to the "Check-Out" booth to complete a simple evaluation to determine their perceptions of the effectiveness of the innovative intervention. When the evaluations were complete, each of the eight critical thinking attribute teams placed their index cards into a hat, and a student won a small prize. All Junior 2, Senior 1 and Senior 2 students were required to attend the Skills Fair. The Skills Fair Team strove to make the event as festive as possible, engaging nursing students with balloons, candy, tri-boards, signs and fun pre and postactivities. The Skills Fair rubrics, scheduling and instructions were shared electronically with students and faculty before the skills fair intervention to ensure adequate preparation and continuous resource availability as students move forward into their future clinical settings.

\section{Research design}

Institutional review board (IRB) approval was obtained from XXX University to conduct this study and protect human subject rights. The explanatory sequential mixed-methods design was employed for this study. The design was chosen to identify what effects a skills fair intervention that had on senior baccalaureate nursing students' achievements on the Kaplan Critical Thinking Integrated Test (KCTIT) and then follow up with individual interviews to explore those test results in more depth. In total, 52 senior nursing students completed the KCTIT; 30 of them participated in the skills fair intervention and 22 of them did not participate. The KCTIT is a computerized 85 -item exam in which 85 equates to $100 \%$, making each question worth one point. It has high reliability and validity (Kaplan Nursing, 2012; Swing, 2014). The reliability value of the KCTIT ranged from 0.72 to 0.89 . A $t$-test was used to analyze the test results.

A total of 11 participants were purposefully selected based on a range of six high achievers and five low achievers on the KCTIT for open-ended one-on-one interviews. Each interview was conducted individually and lasted for about 60 minutes. An open-ended interview protocol was used to guide the flow of data collection. The interviewees' ages ranged from 21 to 30 years, with an average of 24 years. One of 11 interviewees was male. Among them, seven were White, three were Black and one was Indian American. The data collected were used to answer the following research questions: (1) What was the difference in achievements on the KCTIT among senior baccalaureate nursing students who participated in the skills fair intervention and students who did not participate? (2) What were the senior baccalaureate nursing students' perceptions of internal and external factors impacting the development of critical thinking skills during the skills fair intervention? and (3) What were the senior baccalaureate nursing students' perceptions of the skills fair intervention as a critical thinking developmental strategy?

Inductive content analysis was used to analyze interview data by starting with the close reading of the transcripts and writing memos for initial coding, followed by an analysis of patterns and relationships among the data for focused coding. The intercoder reliability was

An evidencebased skills fair intervention 
JRIT

15,1

46

established for qualitative data analysis with a nursing expert. The lead researcher and the expert read the transcript several times and assigned a code to significant units of text that corresponded with answering the research questions. The codes were compared based on differences and similarities and sorted into subcategories and categories. Then, headings and subheadings were used based on similar comments to develop central themes and patterns. The process of establishing intercoder reliability helped to increase dependability, conformability and credibility of the findings (Graneheim and Lundman, 2004). In addition, methods of credibility, confirmability, dependability and transferability were applied to increase the trustworthiness of this study (Graneheim and Lundman, 2004). First, reflexivity was observed by keeping journals and memos. This practice allowed the lead researcher to reflect on personal views to minimize bias. Data saturation was reached through following the recommended number of participants as well as repeated immersion in the data during analysis until no new data surfaced. Member checking was accomplished through returning the transcript and the interpretation to the participants to check the accuracy and truthfulness of the findings. Finally, proper documentation was conducted to allow accurate crossreferencing throughout the study.

\section{Findings}

Quantitative results

Results for the quantitative portion showed there was no difference in scores on the KCTIT between senior nursing students who participated in the skills fair intervention and senior nursing students who did not participate, $t(50)=-0.174, p=0.86>0.05$. The test scores between the nonparticipant group $(M=67.59, \mathrm{SD}=5.81)$ and the participant group $(M=67.88, \mathrm{SD}=5.99)$ were almost equal.

\section{Qualitative results}

Initial coding. The results from the initial coding and generated themes are listed in Table 1. First, the participants perceived the skills fair intervention as "promoting experience" and "confidence" by practicing previously learned knowledge and reinforcing it with active learning strategies. Second, the participants perceived the skills fair intervention as a relaxed, nonthreatening learning environment due to the festive atmosphere, especially in comparison to other learning experiences in the nursing program. The nonthreatening environment of the skills fair intervention allowed students to learn without fear. Third, the majority of participants believed their critical thinking was strengthened after participating. Several participants believed their perception of critical thinking was "enhanced" or "reinforced" rather than significantly changed.

Focused coding results. The final themes were derived from the analysis of patterns and relationships among the content of the data using inductive content analysis (Saldana, 2009). The following was examined across the focused coding process: (1) factors impacting critical thinking skills development during skills fair intervention and (2) skills fair intervention a critical thinking skills developmental strategy.

Table 1. 
Factors impacting critical thinking skills development. The factors impacting the development of critical thinking during the skills fair intervention were divided into two themes: internal factors and external factors. The internal factors were characteristics innate to the students. The identified internal factors were (1) confidence and anxiety levels, (2) attitude and (3) age. The external factors were the outside influences that affected the students. The external factors were (1) experience and practice, (2) faculty involvement, (3) positive learning environment and (4) faculty prompts.

Internal factors. Participant 1 explained her level of confidence kept her calm and permitted her to perform better during the assessment station while anxiety prevented her from thinking clearly and remembering what to do a different station of the Skills Fair. Similarly, Participant 5 said the following:

I think that confidence and anxiety definitely both have a huge impact on your ability to be able to really critically think. If you start getting anxious and panicking you cannot think through the process like you need too. I do not really think gender or age necessarily would have anything to do with critical thinking.

Higher confidence levels were associated with lower anxiety levels and earlier experience with the Skills Fair. Participant 7 said the following:

Definitely the confidence level, I think, the more advanced you get in the program, your confidence just keeps on growing. Level of anxiety, definitely... I think the people who were in the Skills Fair for the first time, had more anxiety because they did not really know to think, they did not know how strict it was going to be, or if they really had to know everything by the book. I think the Skills Fair helped everyone's confidence levels, but especially the Jr. 2's.

Attitude was an important factor in the development of critical thinking skills during the skills fair intervention as participants believed possessing a pleasant and positive attitude meant a student was eager to learn, participate, accept responsibility for completing duties and think seriously. Participant 6 believed attitude contributed to performance in the Skills Fair.

Some participants believed age was a factor as older students have more awareness and life experiences that led to better performance during the skills fair intervention and in other situations. For example, Participant 1, as the oldest participant, said the following:

I feel like, certain things bring critical thinking out in you. And since I'm a little bit older than some of the other students, I have had more life experiences and am able to figure stuff out better. Older students have had more time to learn by trial and error, and this and that.

External factors. Several participants cited experience in the clinical setting helped them think critically during Skills Fair. The participants were able to remember scenarios from their clinical experience and remembered what to do and what not to do in certain situations. For instance, in the experience of Participant 2 in the IV station during Skills Fair, her clinical experience helped her assess the situation in the Skills Fair. Participant 2 narrated as follows:

Like when I had clinical with you, you'd always tell us to know our patients' medications. To always know and be prepared to answer questions - because at first as a Junior 1 we did not do that in the clinical setting. . . and as a Junior 2, I did not really have to know my medications, but with you as a Senior 1, I started to realize that the patients do ask about their meds, so I was making sure that I knew everything before they asked it. And just having more practice with IVs - at first, I was really nervous, but when I got to my preceptorship - I had done so many IVs and with all of the practice, it just built up my confidence with that skill so when I performed that skill during the Fair, I was confident due to my clinical experiences and able to think and perform better.

An evidencebased skills fair intervention 
JRIT

15,1

Faculty involvement was indicated by participants as the most important factor impacting critical thinking skill development during the skills fair intervention. Most of the participants said a familiar instructor facilitated better critical thinking than an unfamiliar instructor did. The faculty members who provided immediate feedback and used critical thinking prompts through Socratic questioning were also perceived by students as a form of critical thinking promotion. The participants referred to an involved instructor who provided prompts during the Skills Fair. Participant 8 stated the following:

I think teachers will always affect the ability to critically think just because you want [to] get the right answer because they are there and you want to seem smart to them [Laugh]. Also, if you are leading in the wrong direction of your thinking - they help steer you back to [in] the right direction so I think that was very helpful.

The participants reported a positive learning environment also contributed to the development of critical thinking, as they were free to learn and not being graded. According to some participants, a positive learning environment was cultivated by the faculty. Participant 1 said the following:

You could tell the faculty really tried to make it more laid back and fun, so everybody would have a good experience. The faculty had a good attitude. I think making it fun and active helped keep people positive. You know if people are negative and not motivated, nothing gets accomplished. The faculty did an amazing job at making the Skills Fair a positive atmosphere.

However, for some of the participants, a positive learning environment depended on their fellow students. The students were randomly assigned alphabetically to groups, and the groups were assigned to starting stations at the Skills Fair. The participants claimed some students did not want to participate and displayed cynicism toward the intervention. The participants believed their cynicism affected the positive learning environment making critical thinking more difficult during the Skills Fair.

Finally, for some participants, receiving prompts from faculty and preceptors prevented them from overlooking errors. Those participants considered avoiding errors as critical thinking. Participant 6 shared the following:

Okay, when [instructor name] was demonstrating the Chevron technique right after we inserted the IV catheter and we were trying to secure the catheter, put on the extension set, and flush the line at what seemed to be all at the same time. I forgot about how you do not want to put the tape right over the hub of the catheter because when you go back in and try to assess the IV site you're trying to assess whether or not it is patent or infiltrated - you have to visualize the insertion site. That was one of the things that I had been doing wrong because I was just so excited that I got the IV in the vein in the first place - that I did not think much about the tape or the tegaderm for sterility. So I think an important part of critical thinking is to be able to recognize when you've made a mistake and stop, stop yourself from doing it in the future (see Table 2).

Skills fair intervention as a developmental strategy for critical thinking. The participants identified the skills fair intervention was effective as a developmental strategy for critical thinking, as revealed in two themes: (1) develops alternative thinking and (2) thinking before doing (See Table 3).

Develops alternative thinking. The participants perceived the skills fair intervention helped enhance critical thinking and confidence by developing alternative thinking. Alternative thinking was described as quickly thinking of alternative solutions to problems based on the latest evidence and using that information to determine what actions were warranted to prevent complications and prevent injury. It helped make better connections through the learning of rationale between knowledge and skills and then applying that knowledge to 
prevent complications and errors to ensure the safety of patients. The participants stated the learning of rationale for certain procedures provided during the skills fair intervention such as the evidence and critical thinking prompts included in the rubrics helped reinforce this connection. The participants also shared they developed alternative thinking after participating in the skills fair intervention by noticing trends in data to prevent potential complications from the faculty prompts. Participant 1 stated her instructor prompted her alternative thinking through questioning about noticing trends to prevent potential complications. She said the following:

Another way critical thinking occurred during the skills fair was when [instructor name] was teaching and prompted us about what it would be like to care for a patient with a fractured hip - I think this was at the 10-minute focused assessment station, but I could be wrong. I remember her asking, "What do you need to be on the look-out for? What can go wrong?" I automatically did not think critically very well and was only thinking circulation in the leg, dah, dah, dah. But she was prompting us to think about mobility alterations and its effect on perfusion and oxygenation. She was trying to help us build those connections. And I think that's a lot of the aspects of critical thinking that gets overlooked with the nursing student - trouble making connections between our knowledge and applying it in practice.

Thinking before doing. The participants perceived thinking before doing, included thinking of how and why certain procedures, was necessary through self-examination prior to taking action. The hands-on situational learning allowed the participants in the skills fair intervention to better notice assessment data and think at a higher level as their previous learning of the skills was perceived as memorization of steps. This higher level of learning allowed participants to consider different future outcomes and analyze pertinent data before taking action.

Participant 9 shared she was able to critically think by considering different outcomes during the Skills Fair before taking action. Participant 9 said the following:

\begin{tabular}{llc}
\hline Themes & Subthemes & Frequency of mentions \\
\hline Internal factors & & 33 \\
& Confidence and anxiety levels & 17 \\
& Attitude & 10 \\
External factors & Age & 6 \\
& Experience and practice & 62 \\
& Faculty involvement & 21 \\
& Positive learning environment & 24 \\
& Faculty prompts & 11
\end{tabular}

\section{An evidence- based skills fair intervention}

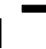


JRIT

15,1
I think what helped me the most is considering outcomes of my actions before I do anything. For instance, if you're thinking, "Okay. Well, I need to check their blood pressure before I administer this blood pressure medication - or the blood pressure could potentially bottom out." I really do not want my patient to bottom out and get hypotensive because I administered a medication that was ordered, but not safe to give. I could prevent problems from happening if I know what to be on alert for and act accordingly. So ultimately knowing that in the clinical setting, I can prevent complications from happening and I save myself, my license, and promote patient safety. I think knowing that I've seen the importance of critical thinking already in practice has helped me value and understand why I should be critically thinking. Yes, we use the 5-rights of medication safety but we also have to think. For instance, if I am going to administer insulin - what do I need to know or do to give this safely? What is the current blood sugar? Has the patient been eating? When is the next meal scheduled? Is the patient NPO for a procedure? Those are examples of questions to consider and the level of thinking that needs to take place prior to taking actions in the clinical setting.

\section{Discussion}

Although the results of quantitative data showed no significant difference in scores on the KCTIT between the participant and nonparticipant groups, during the interviews some participants attributed this result to the test not being part of a course grade and believed students "did not try very hard to score well." However, the participants who attended interviews did identify the skills fair intervention as a developmental strategy for critical thinking by helping them develop alternative thinking and thinking before doing. The findings are supported in the literature as (1) nurses must recognize signs of clinical deterioration and take action promptly to prevent potential complications (Garvey and CNE series 2015) and (2) nurses must analyze pertinent data and consider all possible solutions before deciding on the most appropriate action for each patient (Papathanasiou et al., 2014).

The skills fair intervention also enhanced the development of self-confidence by participants practicing previously learned skills in a controlled, safe environment. The nonthreatening environment of the skills fair intervention allowed students to learn without fear and the majority of participants believed their critical thinking was strengthened after participating. The interview data also revealed a combination of internal and external factors that influenced the development of critical thinking during the skills fair intervention including confidence and anxiety levels, attitude, age, experience and practice, faculty involvement, positive learning environment and faculty prompts. These factors should be considered when addressing the promotion and development of critical thinking.

\section{Conclusions, limitations and recommendations}

A major concern in the nursing profession is the lack of critical thinking in student nurses and new graduates, which influences the decision-making of novice nurses and directly affects patient care and safety (Saintsing et al., 2011). Nurse educators must use evidence-based practice to prepare students to critically think with the complicated and constantly evolving environment of health care today (Goodare, 2015; Newton and Moore, 2013). Evidence-based practice has been advocated to promote critical thinking (Profetto-McGrath, 2005; Stanley and Dougherty, 2010). The skills fair intervention can be one type of evidence-based practice used to promote critical thinking (McCausland and Meyers, 2013; Roberts et al., 2009). The Intervention used in this study incorporated evidence-based practice rationale with critical thinking prompts using Socratic questioning, evidence-based practice videos to the psychomotor skill rubrics, group work, guided discussions, expert demonstration followed by guided practice and blended learning in an attempt to promote and develop critical thinking in nursing students. 
The explanatory sequential mixed-methods design was employed to investigate the effects of the innovative skills fair intervention on senior baccalaureate nursing students' achievements and their perceptions of critical thinking skills development. Although the quantitative results showed no significant difference in scores on the KCTIT between students who participated in the skills fair intervention and those who did not, those who attended the interviews perceived their critical thinking was reinforced after the skills fair intervention and believed it was an effective developmental strategy for critical thinking, as it developed alternative thinking and thinking before doing. This information is useful for nurse educators who plan their own teaching practice to promote critical thinking and improve patient outcomes. The findings also provide schools and educators information that helps review their current approach in educating nursing students. As evidenced in the findings, the importance of developing critical thinking skills is crucial for becoming a safe, professional nurse. Internal and external factors impacting the development of critical thinking during the skills fair intervention were identified including confidence and anxiety levels, attitude, age, experience and practice, faculty involvement, positive learning environment and faculty prompts. These factors should be considered when addressing the promotion and development of critical thinking.

There were several limitations to this study. One of the major limitations of the study was the limited exposure of students' time of access to the skills fair intervention, as it was a oneday learning intervention. Another limitation was the sample selection and size. The skills fair intervention was limited to only one baccalaureate nursing program in one southeastern state. As such, the findings of the study cannot be generalized as it may not be representative of baccalaureate nursing programs in general. In addition, this study did not consider students' critical thinking achievements prior to the skills fair intervention. Therefore, no baseline measurement of critical thinking was available for a before and after comparison. Other factors in the nursing program could have affected the students' scores on the KCTIT, such as anxiety or motivation that was not taken into account in this study.

The recommendations for future research are to expand the topic by including other regions, larger samples and other baccalaureate nursing programs. In addition, future research should consider other participant perceptions, such as nurse educators, to better understand the development and growth of critical thinking skills among nursing students. Finally, based on participant perceptions, future research should include a more rigorous skills fair intervention to develop critical thinking and explore the link between confidence and critical thinking in nursing students.

\section{References}

American Nephrology Nurses Association (ANNA) (2019), "Learning, leading, connecting, and playing at the intersection of nephrology and nursing-2019-2020 strategic plan”, viewed 3 Aug 2019, available at: https://www.annanurse.org/download/reference/association/strategicPlan.pdf.

Arli, S.D., Bakan, A.B., Ozturk, S., Erisik, E. and Yildirim, Z. (2017), "Critical thinking and caring in nursing students", International Journal of Caring Sciences, Vol. 10 No. 1, pp. 471-478.

Benner, P., Sutphen, M., Leonard, V. and Day, L. (2010), Educating Nurses: A Call for Radical Transformation, Jossey-Bass, San Francisco.

Brunt, B. (2005), "Critical thinking in nursing: an integrated review", The Journal of Continuing Education in Nursing, Vol. 36 No. 2, pp. 60-67.

Chun-Chih, L., Chin-Yen, H., I-Ju, P. and Li-Chin, C. (2015), "The teaching-learning approach and critical thinking development: a qualitative exploration of Taiwanese nursing students", Journal of Professional Nursing, Vol. 31 No. 2, pp. 149-157, doi: 10.1016/j.profnurs.2014.07.001.

Clarke, L.W. and Whitney, E. (2009), "Walking in their shoes: using multiple-perspectives texts as a bridge to critical literacy”, The Reading Teacher, Vol. 62 No. 6, pp. 530-534, doi: 10.1598/RT.62.6.7.
An evidence-

based skills fair intervention 
JRIT 15,1

Dykstra, D. (2008), "Integrating critical thinking and memorandum writing into course curriculum using the internet as a research tool”, College Student Journal, Vol. 42 No. 3, pp. 920-929, doi: 10. 1007/s10551-010-0477-2.

Ebright, P., Urden, L., Patterson, E. and Chalko, B. (2004), "Themes surrounding novice nurse nearmiss and adverse-event situations", The Journal of Nursing Administration: The Journal of Nursing Administration, Vol. 34, pp. 531-538, doi: 10.1097/00005110-200411000-00010.

Ennis, R. (2011), "The nature of critical thinking: an outline of critical thinking dispositions and abilities", viewed 3 May 2017, available at: https:/education.illinois.edu/docs/default-source/ faculty-documents/robert-ennis/thenatureofcriticalthinking_51711_000.pdf.

Facione, P.A. (1990), Critical Thinking: A Statement of Expert Consensus for Purposes of Educational Assessment and Instruction, The California Academic Press, Millbrae.

Facione, N.C. and Facione, P.A. (2013), The Health Sciences Reasoning Test: Test Manual, The California Academic Press, Millbrae.

Fero, L.J., Witsberger, C.M., Wesmiller, S.W., Zullo, T.G. and Hoffman, L.A. (2009), "Critical thinking ability of new graduate and experienced nurses", Journal of Advanced Nursing, Vol. 65 No. 1, pp. 139-148, doi: 10.1111/j.1365-2648.2008.04834.x.

Garvey, P.K. and CNE series (2015), "Failure to rescue: the nurse's impact”, Medsurg Nursing, Vol. 24 No. 3, pp. 145-149.

Goodare, P. (2015), "Literature review: 'are you ok there?' The socialization of student and graduate nurses: do we have it right?”, Australian Journal of Advanced Nursing, Vol. 33 No. 1, pp. 38-43.

Graneheim, U.H. and Lundman, B. (2014), "Qualitative content analysis in nursing research: concepts, procedures, and measures to achieve trustworthiness", Nurse Education Today, Vol. 24 No. 2, pp. 105-12, doi: 10.1016/j.nedt.2003.10.001.

Hsu, L. and Hsieh, S. (2013), "Factors affecting metacognition of undergraduate nursing students in a blended learning environment”, International Journal of Nursing Practice, Vol. 20 No. 3, pp. 233-241, doi: 10.1111/ijn.12131.

Ignatavicius, D. (2001), "Six critical thinking skills for at-the-bedside success", Dimensions of Critical Care Nursing, Vol. 20 No. 2, pp. 30-33.

Institute of Medicine (2001), Crossing the Quality Chasm: A New Health System for the 21st Century, National Academy Press, Washington.

James, J. (2013), "A new, evidence-based estimate of patient harms associated with hospital care", Journal of Patient Safety, Vol. 9 No. 3, pp. 122-128, doi: 10.1097/PTS.0b013e3182948a69.

Jones, J.H. (2010), "Developing critical thinking in the perioperative environment", AORN Journal, Vol. 91 No. 2, pp. 248-256, doi: 10.1016/j.aorn.2009.09.025.

Kaplan Nursing (2012), Kaplan Nursing Integrated Testing Program Faculty Manual, Kaplan Nursing, New York, NY.

Kim, J.S., Gu, M.O. and Chang, H.K. (2019), "Effects of an evidence-based practice education program using multifaceted interventions: a quasi-experimental study with undergraduate nursing students", BMC Medical Education, Vol. 19, doi: 10.1186/s12909-019-1501-6.

Longton, S. (2014), "Utilizing evidence-based practice for patient safety", Nephrology Nursing Journal, Vol. 41 No. 4, pp. 343-344.

McCausland, L.L. and Meyers, C.C. (2013), "An interactive skills fair to prepare undergraduate nursing students for clinical experience", Nursing Education Perspectives, Vol. 34 No. 6, pp. 419-420, doi: 10.5480/1536-5026-34.6.419.

McMullen, M.A. and McMullen, W.F. (2009), "Examining patterns of change in the critical thinking skills of graduate nursing students", Journal of Nursing Education, Vol. 48 No. 6, pp. 310-318, doi: 10.3928/01484834-20090515-03.

Moore, Z.E. (2007), "Critical thinking and the evidence-based practice of sport psychology", Journal of Clinical Sport Psychology, Vol. 1, pp. 9-22, doi: 10.1123/jcsp.1.1.9. 
Nadelson, S. and Nadelson, L.S. (2014), "Evidence-based practice article reviews using CASP tools: a method for teaching EBP", Worldviews on Evidence-Based Nursing, Vol. 11 No. 5, pp. 344-346, doi: 10.1111/wvn.12059.

Newton, S.E. and Moore, G. (2013), "Critical thinking skills of basic baccalaureate and accelerated second-degree nursing students", Nursing Education Perspectives, Vol. 34 No. 3, pp. 154-158, doi: 10.5480/1536-5026-34.3.154.

Nibert, A. (2011), "Nursing education and practice: bridging the gap", Advance Healthcare Network, viewed 3 May 2017, available at: https://www.elitecme.com/resource-center/nursing/nursingeducation-practice-bridging-the-gap/.

Oermann, M.H., Kardong-Edgren, S., Odom-Maryon, T., Hallmark, B.F., Hurd, D., Rogers, N. and Smart, D.A. (2011), "Deliberate practice of motor skills in nursing education: CPR as exemplar", Nursing Education Perspectives, Vol. 32 No. 5, pp. 311-315, doi: 10.5480/1536-5026-32.5.311.

Papathanasiou, I.V., Kleisiaris, C.F., Fradelos, E.C., Kakou, K. and Kourkouta, L. (2014), "Critical thinking: the development of an essential skill for nursing students", Acta Informatica Medica, Vol. 22 No. 4, pp. 283-286, doi: 10.5455/aim.2014.22.283-286.

Park, M.Y., Conway, J. and McMillan, M. (2016), "Enhancing critical thinking through simulation", Journal of Problem-Based Learning, Vol. 3 No. 1, pp. 31-40, doi: 10.24313/jpbl.2016.3.1.31.

Paul, R. (1993), Critical Thinking: How to Prepare Students for a Rapidly Changing World, The Foundation for Critical Thinking, Santa Rosa.

Paul, R. and Elder, L. (2008), "Critical thinking: the art of socratic questioning, part III", Journal of Developmental Education, Vol. 31 No. 3, pp. 34-35.

Paul, R. and Elder, L. (2012), Critical Thinking: Tools for Taking Charge of Your Learning and Your Life, 3rd ed., Pearson/Prentice Hall, Boston.

Profetto-McGrath, J. (2005), "Critical thinking and evidence-based practice”, Journal of Professional Nursing, Vol. 21 No. 6, pp. 364-371, doi: 10.1016/j.profnurs.2005.10.002.

Rahman, A. and Applebaum, R. (2011), "What's all this about evidence-based practice? The roots, the controversies, and why it matters", American Society on Aging, viewed 3 May 2017, available at: https://www.asaging.org/blog/whats-all-about-evidence-based-practice-roots-controversiesand-why-it-matters.

Rieger, K., Chernomas, W., McMillan, D., Morin, F. and Demczuk, L. (2015), "The effectiveness and experience of arts-based pedagogy among undergraduate nursing students: a comprehensive systematic review protocol”, JBI Database of Systematic Reviews and Implementation Reports, Vol. 13 No. 2, pp. 101-124, doi: 10.11124/jbisrir-2015-1891.

Robert, R.R. and Petersen, S. (2013), "Critical thinking at the bedside: providing safe passage to patients", Medsurg Nursing, Vol. 22 No. 2, pp. 85-118.

Roberts, S.T., Vignato, J.A., Moore, J.L. and Madden, C.A. (2009), "Promoting skill building and confidence in freshman nursing students with a skills-a-thon", Educational Innovations, Vol. 48 No. 8, pp. 460-464, doi: 10.3928/01484834-20090518-05.

Romeo, E. (2010), "Quantitative research on critical thinking and predicting nursing students' NCLEXRN performance", Journal of Nursing Education, Vol. 49 No. 7, pp. 378-386, doi: 10.3928/ 01484834-20100331-05.

Sackett, D., Rosenberg, W., Gray, J., Haynes, R. and Richardson, W. (1996), "Evidence-based medicine: what it is and what it isn't”, British Medical Journal, Vol. 312 No. 7023, pp. 71-72, doi: 10.1136/ bmj.312.7023.71.

Saintsing, D., Gibson, L.M. and Pennington, A.W. (2011), "The novice nurse and clinical decisionmaking: how to avoid errors", Journal of Nursing Management, Vol. 19 No. 3, pp. 354-359.

Saldana, J. (2009), The Coding Manual for Qualitative Researchers, Sage, Los Angeles.

Scheffer, B. and Rubenfeld, M. (2000), “A consensus statement on critical thinking in nursing”, Journal of Nursing Education, Vol. 39 No. 8, pp. 352-359. 
JRIT

15,1

\section{4}

Stanley, M.C. and Dougherty, J.P. (2010), "Nursing education model. A paradigm shift in nursing education: a new model”, Nursing Education Perspectives, Vol. 31 No. 6, pp. 378-380, doi: 10. 1043/1536-5026-31.6.378.

Swing, V.K. (2014), "Early identification of transformation in the proficiency level of critical thinking skills (CTS) for the first-semester associate degree nursing (ADN) student", doctoral thesis, Capella University, Minneapolis, viewed 3 May 2017, ProQuest Dissertations \& Theses database.

Turner, P. (2005), "Critical thinking in nursing education and practice as defined in the literature", Nursing Education Perspectives, Vol. 26 No. 5, pp. 272-277.

Twibell, R., St. Pierre, J., Johnson, D., Barton, D., Davis, C. and Kidd, M. (2012), "Tripping over the welcome mat: why new nurses don't stay and what the evidence says we can do about it", American Nurse Today, Vol. 7 No. 6, pp. 1-10.

Watson, G. and Glaser, E.M. (1980), Watson Glaser Critical Thinking Appraisal, Psychological Corporation, San Antonio.

Wittmann-Price, R.A. (2013), "Facilitating learning in the classroom setting", in Wittmann-Price, R.A., Godshall, M. and Wilson, L. (Eds), Certified Nurse Educator (CNE) Review Manual, Springer Publishing, New York, NY, pp. 19-70.

\section{Corresponding author}

E-Ling Hsiao can be contacted at: ehsiao@valdosta.edu

For instructions on how to order reprints of this article, please visit our website:

www.emeraldgrouppublishing.com/licensing/reprints.htm

Or contact us for further details: permissions@emeraldinsight.com 